\title{
Green and hawksbill turtle abundance and population dynamics at foraging grounds in Bonaire, Caribbean Netherlands
}

\author{
Frank F. Rivera-Milán ${ }^{1,2, *}$, Mabel Nava ${ }^{1}$, Kaj Schut ${ }^{1}$, Fernando Simall ${ }^{1,2,3}$ \\ ${ }^{1}$ Sea Turtle Conservation Bonaire, Kaya Korona 53, Kralendijk, Bonaire, Caribbean Netherlands \\ ${ }^{2}$ WILDCONSCIENCE, Kaya Platina 42, Kralendijk, Bonaire, Caribbean Netherlands \\ ${ }^{3}$ CARMABI Foundation, Piscaderabaai z/n, Willemstad, Curaçao, Netherlands Antilles
}

\begin{abstract}
Green turtles Chelonia mydas and hawksbill turtles Eretmochelys imbricata are negatively impacted by natural and anthropogenic disturbances. Unknown numbers of turtles are killed annually in the coastal waters of Bonaire and Klein Bonaire, Caribbean Netherlands. We used $\mathrm{N}$-mixture models, conventional distance sampling and the multiple Lincoln-Petersen method to estimate abundance from transect-count and net-capture surveys. Maximum likelihood and Bayesian generalised linear models were used to assess trends in annual abundance in 2003-2018, and a Bayesian state-space logistic model was developed to generate the posterior distributions of population parameters and make abundance predictions for 2019-2030. Mean \pm SE annual abundance was $555 \pm 149$ green turtles $(2.5$ th and 97.5 th percentiles $=337,943)$ and $70 \pm 13$ hawksbill turtles $(49,101)$, and there were no trends in western Bonaire and Klein Bonaire in 2003-2018. Mean annual abundance was $348 \pm 135$ green turtles $(171,731)$ and there was a positive trend inside Lac Bay, southeast Bonaire, 2003-2018. Green turtles have higher population growth rate and carrying capacity, and therefore can sustain higher human-induced mortality than hawksbill turtles. However, under low mortality rates $(<0.100)$, both species can fluctuate stably between the lower and upper limits of the carrying capacity. The methodology implemented can be adapted to estimate sea turtle abundance, monitor and model their population dynamics, and assess the negative impact of human-induced mortality in other Caribbean islands.
\end{abstract}

KEY WORDS: Chelonia mydas $\cdot$ Eretmochelys imbricata $\cdot$ Abundance $\cdot N$-mixture model $\cdot$ Distance sampling $\cdot$ Multiple Lincoln-Petersen method · Generalised linear model $\cdot$ Bayesian state-space logistic model

\section{INTRODUCTION}

Sea turtle transect-count and net-capture surveys can be used to monitor and model temporal changes in abundance in the coastal waters of Caribbean islands (Bjorndal et al. 2005, Patrício et al. 2014, García-Cruz et al. 2015, Strindberg et al. 2016). However, a flexible modelling framework is needed to account for the observation variance associated with detection or capture probability and the process variance associated with biological and environmental

${ }^{*}$ Corresponding author: riveramilanff@gmail.com factors driving temporal changes in abundance (Bjorndal et al. 2005, Chaloupka \& Balazs 2007, Kéry \& Schaub 2012, Newman et al. 2014, Hostetler \& Chandler 2015, Rivera-Milán et al. 2018). In the coastal waters of Bonaire and Klein Bonaire, Caribbean Netherlands, sea turtles are negatively impacted by natural and anthropogenic disturbances, and unknown numbers are killed annually by fishermen, boaters and poachers (Schut et al. 2018). Additive mortality from natural and anthropogenic disturbances can cause declines in abundance and hinder

(C) The authors 2019. Open Access under Creative Commons by Attribution Licence. Use, distribution and reproduction are unrestricted. Authors and original publication must be credited. 
local and regional conservation efforts to maintain or enhance population levels in a changing environment (Chaloupka \& Balazs 2007, Chaloupka et al. 2008, Saba et al. 2012, García-Cruz et al. 2015, Casale \& Heppell 2016, Mazaris et al. 2017, Schut et al. 2018).

Based on 219 reported incidents, at least 25 green turtles Chelonia mydas and 6 hawksbill turtles Eretmochelys imbricata were killed in Bonaire and Klein Bonaire in 2011-2018. Of these 31 known lethal incidents, $14(45 \%)$ were related to fishing, 11 (36\%) were related to poaching, and $6(19 \%)$ were related to boating accidents, resulting in an average of 4 deaths $\mathrm{yr}^{-1}(\mathrm{SD}=1,95 \% \mathrm{CI}=3-6)$. For more information about lethal and nonlethal incidents reported to Sea Turtle Conservation Bonaire (STCB), refer to Schut et al. 2018 and previous annual reports available at www.bonaireturtles.org. In response to natural and anthropogenic disturbances, staff and volunteers working with STCB have been conducting collaborative activities, including rescues, beach clean-ups, community outreach and educational campaigns, as well as nest-monitoring, satellite tracking and other research, to better understand sea turtle ecology locally and regionally (Becking et al. 2016, Bjorndal et al. 2017, Christianen et al. 2019, J. Van der Zee pers. comm.). In addition, transect-count and net-capture surveys have been conducted annually since 2003 to estimate sea turtle abundance at foraging grounds along the west coast of Bonaire, the entire coast of neighbouring Klein Bonaire and the interior of Lac Bay in southeast Bonaire.

Here, we present an analysis of green and hawksbill turtle transect-count and net-capture survey data using $N$-mixture models to estimate and monitor annual abundance in 2003-2018, accounting for detection and capture probability (Royle 2004, Kéry et al. 2009, Kéry \& Schaub 2012). For comparison, we also estimated abundance from transect-count surveys using conventional distance sampling (Buckland et al. 2001) and from net-capture surveys using the multiple Lincoln-Petersen method (Grimm et al. 2014). To assess trends in annual abundance, we used maximum likelihood generalised linear models (Faraway 2006) and Bayesian generalised linear models (Thompson 2014). Lastly, we used survey-based abundance estimates to develop a Bayesian statespace logistic model, generate the posterior distributions of maximum population growth rate, population carrying capacity, equilibrium popula- tion abundance, maximum sustainable humaninduced mortality rate and maximum sustainable total number of deaths from human-induced mortality. We make model-based abundance predictions for 2019-2030, accounting for observation and process variance and uncertainty from human-induced mortality (Rivera-Milán et al. 2018).

\section{MATERIALS AND METHODS}

\subsection{Transect-count and net-capture surveys}

The surveyed areas were characterized by fringing reefs with coral, sand and rubble, and a shallow lagoon with seagrass beds similar to other areas in the Caribbean (e.g. the offshore territorial islands of Puerto Rico, see Patrício et al. 2014). Transect-count surveys were conducted in western Bonaire and Klein Bonaire (area $=4 \mathrm{~km}^{2}$; between $12^{\circ} 20^{\prime} \mathrm{N}, 68^{\circ} 24^{\prime} \mathrm{W}$ and $12^{\circ} 00^{\prime} \mathrm{N}, 68^{\circ} 16^{\prime} \mathrm{W}$; Table 1, Fig. 1A). Net-capture surveys were conducted inside Lac Bay in southeast Bonaire (area $=7 \mathrm{~km}^{2} ; 12^{\circ} 06^{\prime} \mathrm{N}$,

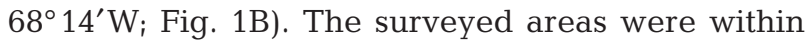
the boundaries of the National Marine Park (www. stinapabonaire.org/bonaire-national). Transect-count and net-capture survey procedures were standardized and covered similar areas in all years, but the coordinates were not fixed in 2003-2017. The coordinates of 36 transects (each $1000 \mathrm{~m}$ long) and 28 points were fixed in 2018 and will remain fixed in future surveys (Fig. 1).

A mean \pm SD of $37 \pm 3$ transects $(95 \% \mathrm{CI}=33-43)$ and $23 \pm 7$ points (15-31) were covered per survey time period in February-May and June-December 2003-2018. Survey effort was kept as constant as possible, with 3-5 transect-count and net-capture surveys per day, under good weather conditions. Sur-

Table 1. Transect average area $\left(\mathrm{km}^{2}\right)$ covered by rubble, coral or sand substrates with standard errors and 2.5 th and 97.5 th percentiles in northwest and southwest Bonaire and Klein Bonaire in February-May 2018

\begin{tabular}{|lcccccc|}
\hline Region & \multirow{2}{*}{ Area $\left(\mathrm{km}^{2}\right)$} & Substrate & Mean & SE & 2.5 th & 97.5th \\
\hline Northwest Bonaire & \multirow{2}{*}{1.75} & Rubble & 0.96 & 0.02 & 0.92 & 1.00 \\
& & Coral & 0.72 & 0.03 & 0.66 & 0.78 \\
\multirow{2}{*}{ Southwest Bonaire } & \multirow{2}{*}{1.57} & Sand & 0.07 & 0.03 & 0.03 & 0.16 \\
& & Rubble & 0.78 & 0.05 & 0.69 & 0.88 \\
& & Coral & 0.44 & 0.04 & 0.37 & 0.53 \\
Klein Bonaire & \multirow{2}{*}{0.68} & Sand & 0.34 & 0.05 & 0.26 & 0.45 \\
& & Rubble & 0.32 & 0.03 & 0.27 & 0.38 \\
& & Coral & 0.29 & 0.03 & 0.24 & 0.36 \\
& & Sand & 0.07 & 0.03 & 0.03 & 0.16 \\
\hline
\end{tabular}



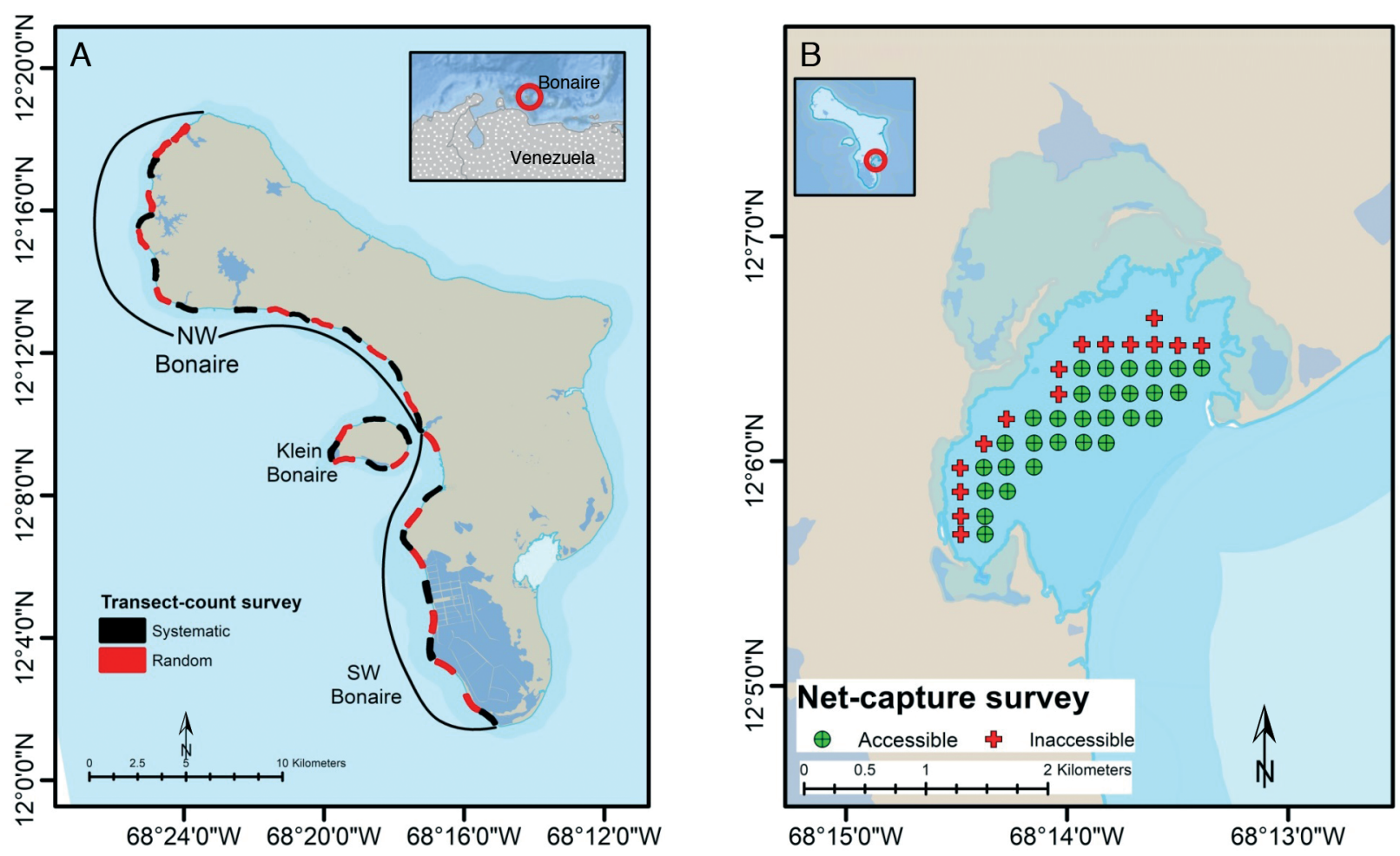

Fig. 1. (A) Transect-count surveys along the west coast of Bonaire and Klein Bonaire in February-May 2018 and (B) netcapture surveys inside Lac Bay, southeast Bonaire, in June-December 2018. The black solid line delineates the NW and SW regions of Bonaire

vey-specific covariates, such as the number of observers and counting or netting time ('soaking' time), were also included in $\mathrm{N}$-mixture models. An average of $6 \pm 1$ observers (4-8) spent about $35 \pm 6 \min (25-49)$ per transect-count survey. The observers snorkelled parallel to the coast at a distance of about $10-25 \mathrm{~m}$ from each other, covering the reef contour from shallow water to about 20-25 m deep, recording the time and location of sea turtles detected. An average of 8 \pm 1 observers (6-10) spent about $64 \pm 6$ min (53-77) per net-capture survey. Sea turtles were captured in a $200 \mathrm{~m}$ long $\times 5 \mathrm{~m}$ wide net that was deployed from a small motor boat. The observers lined up and snorkelled parallel to the net to remove sea turtles quickly and take them to the boat for marking with alloy self-piercing tags and internal passive integrated transponders, collecting morphometric data and blood samples, and taking photos and other information, such as the presence of scars and external fibropapilloma tumours.

Few hawksbill turtles were captured inside Lac Bay, and most of the green turtles captured were juveniles, with maximum straight-line carapace lengths averaging $49.80 \pm 9.73 \mathrm{~cm}$ (49.21-50.39). In comparison, maximum straight-line carapace lengths of green turtles nesting at local beaches averaged 103.31 \pm
$9.27 \mathrm{~cm}$ (95.56-111.06). Green turtles with maximum straight-line carapace lengths $<80-85 \mathrm{~cm}$ can be considered juveniles (Kubis et al. 2009, Patrício et al. 2014). Lac Bay offers suitable foraging resources for the development of green turtles from rookeries across the Caribbean (Bjorndal et al. 2017, Christianen et al. 2019, J. Van der Zee et al. pers. comm.). Because green turtles become long-term residents, moving mainly between the outer reef and the interior of Lac Bay (Christianen et al. 2019), we analysed net captures separately from transect counts in western Bonaire and Klein Bonaire.

\section{2. $N$-mixture models}

We used $N$-mixture models to estimate abundance and detection or capture probability from transectcount and net-capture surveys in 2003-2018 (Royle 2004, Kéry et al. 2009, Kéry \& Schaub 2012). Transect counts and net captures $C_{i j}$ were defined as conditionally independent binomial random variables with index $N_{i j}$ (i.e. sea turtle abundance at transect or net $i$ and time $j$ ) and detection or capture probability $P_{i j}$ (i.e. sea turtles counted at transect or captured at net $i$ and time $j$ ). For example, assuming abundance can 
be represented by the Poisson distribution and detection or capture probability can be represented by the binomial distribution, the integrated likelihood was

$$
\begin{aligned}
& L\left(\lambda, P_{i j} \mid C_{i j}\right)= \\
& \left.\stackrel{\prod_{i=1}^{R}}{\sum_{N_{i}=\max \left(C_{i}\right)}^{\infty}}\left[\prod_{j=1}^{J} \operatorname{Binomial}\left(C_{i j} \mid N_{i j}, P_{i j}\right)\right] \operatorname{Poisson}\left(N_{\mathrm{ij}} \mid \lambda\right)\right\}
\end{aligned}
$$

An additive normal random effect was used to account for extra-Poisson variation in abundance $\lambda$. For example, $\log \left(\lambda_{i j}\right)=\beta_{0}+\beta_{1}\left(x_{i j}\right)+\beta_{2}\left(y_{i j}\right)+\varepsilon_{i j}$ for region $x_{i j}$ and month $y_{i j}$, with error $\varepsilon_{i j} \sim$ Normal $(0$, $\sigma_{\lambda_{i j}}^{2}$ ). A logistic regression model was used to account for extra-binomial variation in detection or capture probability. For example, logit $\left(P_{i j}\right)=\beta_{0}+\beta_{1}\left(x_{i j}+\beta_{2}\left(y_{i j}\right)\right.$ $+\varepsilon_{i j}$, where $x_{i j}$ and $y_{i j}$ are survey-specific or site-specific covariates for transect or net $i$ and time $j$, with error $\varepsilon_{i j} \sim$ Normal $\left(0, \sigma_{\lambda_{i j}}^{2}\right)$. Region (Klein Bonaire, northwest and southwest Bonaire for transect counts; Fig. 1A), survey time period (February-May for transect counts and June-December for net captures in 2003-2018), counting and netting time (minutes elapsed from survey start to end) and the number of observers (4-10) were modelled as abundance and detection or capture probability covariates. In 2018, bottom substrate (transect average area covered by coral, rubble or sand measured at 0,500 and $1000 \mathrm{~m}$; Table 1) and transect surveyed area (mean $=0.11 \pm$ $0.04 \mathrm{~km}^{2}, 95 \% \mathrm{CI}=0.06-0.22 \mathrm{~km}^{2}$ ) were modelled as abundance and detection or capture probability covariates, and the number of divers and boats (humaninduced disturbance) and visibility (low: $<10 \mathrm{~m}$, medium: 11-20 m and high: $>20 \mathrm{~m}$ ) were modelled as detection or capture probability covariates. To explore the covariate effects, we analysed the transectcount and net-capture survey data in 2003-2018 and 2018 only. Continuous covariates, such as counting and netting time, were standardized (i.e. $z=$ [raw score mean score $] / \mathrm{SD}$, so that mean $=0$ and $\mathrm{SD}=1$ ).

We used Poisson-binomial mixture models, zeroinflated Poisson and negative binomial mixture models as implemented in PRESENCE ver. 2.12.32 (Hines 2019) and UNMARKED ver. 0.12-3 (Fiske et al. 2019). Model selection based on minimization of Akaike's information criterion (AIC $=-2 \ln \hat{L}+2 q$, where $\hat{\mathrm{L}}=$ maximised likelihood, $\mathrm{q}=$ number of parameters) and precision measures (e.g. $\mathrm{CV}=$ $\mathrm{SE} / \mathrm{mean}$ ) favoured the use of zero-inflated Poisson mixture models for green turtle transect counts and Poisson-binomial mixture models for green turtle net captures and hawksbill turtle transect counts. $N$-mixture models with $\Delta \mathrm{AIC}<2$ were considered equally supported by the data. The fit of fully parameterized
$N$-mixture models (e.g. $\lambda[$ region + month + year $], P[t$ region + month + year + observer + counting or netting time]) was evaluated with the Pearson $\chi^{2}$-statistic. Abundance was estimated for each year separately, using the model or models with the lowest AIC values and highest AIC weights. Bootstrapping (resamples $=999)$ and model averaging $(\Delta \mathrm{AIC}<2)$ were used to account for model selection uncertainty.

The assumptions of the simplest $N$-mixture model were: (1) population closure during the survey time period (i.e. constant sea turtle abundance [no births or deaths and no immigrants or emigrants]); (2) constant detection or capture probability (i.e. the same for all sea turtles [juveniles, subadults or adults, tagged or untagged] at transect or net $i$ and time $j$ ); and (3) no false positives (i.e. no double counts at transect or net $i$ and time $j$ ). The first 2 assumptions were relaxed by including month and year as covariates in the models and by indexing transect counts and net captures $C_{i j k}$ for surveyed area $i$, month $j$ and year $k$. The last assumption was likely met by using tags, transponders and photos in the case of net captures, and by recording detection time and location and discarding possible double counts in the case of transect counts. Results are presented as means and bootstrapped standard errors with 2.5 th and 97.5 th percentiles as the limits for $95 \%$ confidence intervals (CIs). Details of other statistical analyses are provided with corresponding results. Significance was accepted at $\mathrm{p}<0.05$.

\subsection{Conventional distance sampling}

Conventional distance sampling was used for transect-count surveys in 2018 only. Distance sampling will be used in future surveys. For transect-count surveys in 2018, we assumed that the half-normal key function (i.e. $\exp \left[-y^{2} / 2 \sigma^{2}\right]$ ) adequately represented the rate (scale parameter $\sigma$ ) at which detection probability of single sea turtles decreased with perpendicular distances $y$ from the transect centrelines. We also assumed that sea turtles were present in the surveyed areas during the transect counts, and therefore that detection probability had 2 main components (i.e. $P_{a}=$ sea turtle availability for detection, and $P_{d}=$ detectability of available sea turtles). Sea turtles may or may not be available for detection during the surveys, for example, when they dive, hide and remain motionless in response to the observers. The half-normal key function with 2 distance categories (0-30 and 31-90 m) was used to estimate detectability and abundance (i.e. the number of green and hawksbill 
turtles in $4 \mathrm{~km}^{2}$ ). From $N$-mixture models and distance sampling detection probabilities, we derived speciesspecific estimates of availability (i.e. $P_{a}=P_{d a} / P_{d i}$ Burton \& Rivera-Milán 2014). The delta method was used to approximate availability standard errors, and species-specific multipliers were included in the distance sampling abundance estimator (Thomas \& Marques 2012). We post-stratified the data by species to generate detection functions (Buckland et al. 2001).

The basic assumptions of distance sampling were: (1) adequate representation of sea turtle detectability by the half-normal key function; (2) certain detection of sea turtles at the transect centrelines; (3) detection of sea turtles at initial locations, before any behavioural responses; (4) accurate allocation of sea turtles to the distance categories; and (5) random distribution of sea turtles with respect to transect locations. The half-normal key function has been proven to be flexible, efficient and robust for modelling and estimation (Buckland et al. 2001). In addition, trained observers did not likely miss sea turtles at transect centrelines; the third and fourth assumptions were likely met by using 2 wide distance categories; and the last assumption was met with the survey design (Fig. 1A). Details of conventional distance sampling and the abundance estimator used are provided in Buckland et al. (2001, 2015), Burton \& Rivera-Milán (2014), Thomas et al. (2010) Thomas \& Marques (2012), and Rivera-Milán et al. (2018). For the analysis, we used DISTANCE 7.1 ver. 2 (Thomas et al. 2010) and UNMARKED (Fiske et al. 2019). Results are presented as means and bootstrapped standard errors with 2.5 th and 97.5 th percentiles as the limits for $95 \%$ CIs.

\subsection{Multiple Lincoln-Petersen method}

For comparison with abundance estimates of $N$ mixture models in 2003-2018, and because only a low number of green turtles were recaptured from those captured, tagged and released per survey time period inside Lac Bay (mean $\pm \mathrm{SD}=6 \pm 3,95 \% \mathrm{CI}=$ 2-15), we estimated abundance using the multiple Lincoln-Petersen method (Grimm et al. 2014). We estimated mean abundance for $k-1$ net-capture surveys by pooling the captures $n_{1}$ of the first time period (e.g. the first $2 \mathrm{wk}$ of June) and the captures $n_{2}$ and recaptures $m_{2}$ of subsequent time periods (e.g. the last $2 \mathrm{wk}$ of June and the first $2 \mathrm{wk}$ or last $2 \mathrm{wk}$ of July and August). We used Chapman's bias-corrected modification of the Lincoln-Petersen estimator for abundance and variance estimation. We esti- mated a single variance by summing all the variances and dividing by $(k-1)^{2}$. By combining the captures from consecutive net-capture surveys and using the multiple Lincoln-Petersen method, we relaxed the basic assumptions, which are similar to other closed population methods, i.e. population closure during and independence between survey time periods, equal capture probability for all sea turtles and no tag loss or transponder malfunction to allow unique identification. For more information about the multiple Lincoln-Petersen method and the abundance estimator used, refer to Grimm et al. (2014). Results are presented as means and bootstrapped standard errors with 2.5 th and 97.5 th percentiles as the limits for $95 \%$ CIs.

\subsection{Generalised linear models (GLMs)}

To assess trends in annual abundance in 2003-2018, we used maximum likelihood GLMs (Faraway 2006) and Bayesian GLMs (Thompson 2014). For netcapture surveys, we combined green turtle abundance estimates from $N$-mixture models and the multiple Lincoln-Petersen method in June-December 2003-2018. GLMs consist of a linear predictor (i.e. $\eta=$ $\beta_{0}+\beta_{1} x$, where $\beta_{0}$ is the intercept and $\beta_{1}$ is the slope), a link function (i.e. $g[\mu]=\eta$, where $g$ is a smooth, monotonic function) and a random component with abundance $y_{1}, \ldots y_{n}$ assumed to be independent with density $y_{i}$ generated from the exponential family of distributions. For example, after log-transforming abundance $y$, we used the normal distribution with mean $\mu_{i}$ and variance $\sigma^{2}$, identity function $g\left(\mu_{i}\right)=\mu_{i}$, and linear predictor $\eta_{i}=\beta_{0}+\beta_{1} x_{i}$ :

$$
\begin{gathered}
y_{i} \sim \operatorname{Normal}\left(\mu_{i}, \sigma^{2}\right) \\
\mu_{i}=\beta_{0}+\beta_{1} x_{i}
\end{gathered}
$$

To assess the relationship between abundance $y$ and year $x$, we estimated the regression parameters $\beta_{0}$ and $\beta_{1}$ and variance $\sigma^{2}$ with the 'glm' function in $\mathrm{R}$ ver. 3.5.1 (R Development Core Team 2018). We used graphs to assess model fit patterns (e.g. scatterplots of residuals against fitted values) and robust standard errors (e.g. unbiased sandwich estimator) available in STATA ver. 16.0 (Acock 2016) and R package SANDWICH ver. 2.5.1 (Zeileis 2004). Serial correlation of residuals over time was negligible (e.g. Durbin-Watson's $d$-statistic $=2.00-2.16$; BreuschGodfrey's Lagrange multiplier test and Durbin's alternative test: $\chi^{2}=0.58-0.68, \mathrm{df}=1$, all $\mathrm{p}>0.41$ ). We 
used the $z$-statistic to determine if trends in annual abundance were significant $(p<0.05)$. Slope estimates with $95 \%$ CIs excluding 0 also provided information about the strength of trends in annual abundance.

In addition, we used Bayesian GLMs, under the assumption that $\beta_{0}, \beta_{1}$ and $\sigma^{2}$ represented random realizations from prior distributions (e.g. $\beta_{0} \sim$ Normal $[5,5], \beta_{1} \sim$ Normal $[1,1], \sigma \sim$ Uniform $\left.[0,5]\right)$. Gibbs and random-walk Metropolis-Hastings samplers were used to generate the posterior distributions of $\beta_{0}, \beta_{1}$ and $\sigma^{2}$, given $y$. Package CALL ver. 2.4.5 was used to integrate R and STATA (Haghish 2016). We conducted 250000 iterations with the first 50000 iterations used as a burn-in period. We generated 3 Markov chains with different initial parameter values and used trace plots and node summary statistics to check for convergence of the Markov chain Monte Carlo (MCMC) algorithm (e.g. Brooks-Gelman-Rubin's diagnostic $R$ statistic < 1.10; Gelman \& Hill 2007). Markov chains were thinned by 25 to obtain samples of 8000 iterations. Results are presented as means with MCMC standard deviations and medians with 2.5 th and 97.5th percentiles for the limits of $95 \%$ credible intervals. Slope posterior distributions with $95 \%$ credible intervals excluding 0 provided evidence of trends in annual abundance.

\subsection{Bayesian state-space logistic model}

Temporal changes in abundance were modelled with a discrete form of the standard logistic equation in the presence of human-induced mortality (RiveraMilán et al. 2018):

$$
N_{t+1}=N+r_{\max } N_{t}\left[1-\left(\frac{N_{t}}{K}\right)\right]-M_{t}
$$

where $r_{\max }$ is the maximum intrinsic rate of population growth, $K$ is the population carrying capacity, $N_{t}$ is the true unknown abundance state of the population, and $M_{t}$ is the total number of deaths from human-induced mortality in year $t$. The total number of deaths from human-induced mortality $M_{t}=N_{t} m_{t}$, where $m_{t}$ is the mortality rate between year $t$ and $t+1$. Because data about movements and demographic rates were insufficient, population growth rate represents an integrated parameter (i.e. [births + immigrants] - [deaths + emigrants]) for green and hawksbill turtles in the coastal waters of Bonaire and Klein Bonaire. In addition, because data about humaninduced mortality were limited to 31 known lethal incidents in 2011-2018, we generated mortality rates randomly as part of the MCMC algorithm with the uniform distribution (e.g. $m \sim$ uniform [0.010, 0.100]). We reparameterized the unknown abundance state as a proportion of population carrying capacity $N_{t} / K$ to reduce the autocorrelation of MCMC samples. We assumed that the error of state model predictions $\varepsilon$ was lognormally distributed with mean 0 and an estimated standard deviation $\sigma_{\text {process }}$. Based on this reparameterization, abundance was projected forward in time according to:

$$
P_{t+1}=\left[P_{t}+r_{\max } P_{t}\left(1-P_{t}\right)-\frac{M_{t}}{K}\right] \mathrm{e}^{\varepsilon_{t}}
$$

We modelled abundance proportion of Year 1 using a lognormal distribution with mean $P_{0}$ and variance $\sigma_{P_{0}}^{2}$ :

$$
P_{1} \sim \operatorname{lognormal}\left(P_{0}, \sigma_{P_{0}}^{2}\right)
$$

While the process model in the state-space formulation accounted for our incomplete understanding of green and hawksbill turtle population dynamics, we also needed to relate true abundance state to the surveys to account for observation variance. We specified that abundance $y_{t}$ and observation variance $\sigma_{t, \text { survey }}^{2}$ were estimated from the transect-count and net-capture surveys in 2003-2018. For net-capture surveys, we combined abundance estimates from $N$ mixture models and the multiple Lincoln-Petersen method. Because the distribution of survey-based abundance estimates tended to be positively skewed, we assumed a lognormal distribution for the observation variance. We transformed abundance estimates to the natural logarithm scale by transforming the bootstrap standard error to the standard deviation of the corresponding lognormal distribution. To complete the observation model of the state-space formulation, the true unknown abundance state $N_{t}=P_{t} K$ was related to estimated abundance with:

$$
\log \left(y_{t}\right)=\log \left(P_{t} K\right)+u_{t}
$$

where:

$$
u_{t} \sim \operatorname{Normal}\left(0, \sigma_{t, \text { survey }}^{2}\right)
$$

Assuming linear density dependence, we derived the following parameters

$$
\begin{aligned}
& m_{\mathrm{ms}}=\frac{r_{\mathrm{max}}}{2} \\
& N_{\mathrm{eq}}=\frac{K}{2} \\
& M_{\mathrm{ms}}=\frac{r_{\mathrm{max}} K}{4}
\end{aligned}
$$


where $m_{\mathrm{ms}}$ is the maximum sustainable humaninduced mortality rate, $N_{\text {eq }}$ is the equilibrium population abundance, and $M_{\mathrm{ms}}$ is the maximum sustainable total number of deaths from human-induced mortality. We assumed that all human-induced mortality occurred after reproduction and that all sea turtles had equal mortality probability. Most egg laying and hatching occurs between May and November, with a peak in nesting activity between June and September (see Schut et al. 2018 and previous STCB reports). We modelled mortality from natural and anthropogenic disturbances as additive, although compensation was allowed through density-dependent population growth.

Unobserved population parameters and unknown abundance states were estimated under the assumption of conditional independence for each time step. We specified uniform prior distributions with wide but realistic ranges for maximum population growth rate (e.g. $r_{\max } \sim$ uniform $\left.[0.010,2.000]\right)$, population carrying capacity (e.g. $K \sim$ uniform [100, 10 000]), and the mean of initial population abundance on the log scale (e.g. $P_{0} \sim$ uniform $\left.[-5,0]\right)$. For the standard deviations of process error and initial annual abundance proportion, we also specified uniform priors (e.g. $\sigma_{\text {process }}$ and $\sigma_{P_{0}} \sim$ uniform $[0,5]$ ). To generate parameter posterior distributions, we ran JAGS ver. 4.3.0 (Plummer 2003) with R2JAGS ver. 0.5-7 (Su \& Yajima 2015). We generated 250000 iterations and used the first 50000 iterations as the burn-in period. We thinned 3 Markov chains by 25 for samples of 8000 iterations. Convergence of the MCMC algorithm was checked with trace plots and node summary statistics (Gelman \& Hill 2007). Results are presented as means with MCMC standard deviations and medians with 2.5 th and 97.5 th percentiles for the limits of $95 \%$ credible intervals.

\section{RESULTS}

\subsection{Transect count surveys in western Bonaire and Klein Bonaire}

\subsubsection{Green turtles}

We detected an average of $240 \pm 36$ green turtles (mean \pm SD; $95 \%$ CI $=179-322$ ) per survey time period in February-May 2003-2018. The fully parameterized zero-inflated Poisson mixture model fit the data in 2003-2018 and $2018\left(\chi^{2}=21.58\right.$ and 22.64, $\mathrm{df}=19, \mathrm{p}=0.25$ and 0.31, respectively; Tables $2 \& 3$ ). Based on AIC values and weights in 2003-2018 (Table 2), region was the most important abundance covariate $\left(\beta_{1}=0.191, \mathrm{SE}=0.009, \mathrm{CI}=0.174-0.209\right)$; and survey-specific detection probability $P(t)$ was mainly influenced by counting time $\left(\beta_{1}=0.674, \mathrm{SE}=\right.$ $0.300, \mathrm{CI}=0.293-1.551$ ) and the number of observers $\left(\beta_{1}=0.015, \mathrm{SE}=0.011, \mathrm{CI}=0.004-0.054\right)$. The zeroinflated Poisson mixture model with constant abundance $\lambda($.) and survey-specific detection probability with transect average area covered by rubble as a detection covariate received the strongest support from the data in 2018 (Table 3). However, region influenced abundance $\left(\beta_{1}=0.161, \mathrm{SE}=0.095, \mathrm{CI}=0.055-0.470\right)$, and transect average area covered by rubble influenced detection probability and abundance $\left(\beta_{1}=\right.$ $0.385, \mathrm{SE}=0.131, \mathrm{CI}=0.201-0.737$ and $\beta_{1}=0.197, \mathrm{SE}=$ 0.086, CI =0.087-0.447, respectively; Table 3). Based on AIC values and weights, the zero-inflated Poisson mixture model with region as an abundance covariate and transect average area covered by rubble as a detection probability and abundance covariate received little support from the data and did not rank among the top models (i.e. $\lambda[$ region + rubble], $P[t$, rubble], $\Delta \mathrm{AIC}=2.89, \mathrm{q}=9$, AIC weight $=0.06$; Table $3)$. However, transect average area covered by rubble and green turtle abundance were higher in northwest than southwest Bonaire and Klein Bonaire $(z=$ 3.71-24.38, all $\mathrm{p}<0.001$; Tables $1 \& 4$ ).

Mean \pm SE annual detection probability was 0.290 $\pm 0.068(2.5$ th and 97.5 th percentiles $=0.184,0.457)$. Mean annual abundance was $555 \pm 149$ green turtles (337, 943; Table 5). Maximum likelihood and Bayesian GLMs generated similar results and showed no trends in annual abundance in 2003-2018 $\left(\beta_{1}=0.015, \mathrm{SE}=\right.$ $0.012, \mathrm{CI}=-0.008-0.038, z=1.28, \mathrm{p}=0.21$ and $\beta_{1}=$ $0.015, \mathrm{SD}=0.014, \mathrm{CI}=-0.012-0.041$, respectively; Table 5, Fig. 2). Realizations of Markov chains and node summary statistics showed convergence of the MCMC algorithm for Bayesian GLMs $(R=1.00-1.03)$.

Based on $N$-mixture model averaging, mean $\pm \mathrm{SE}$ detection probability $P_{d a}$ was $0.411 \pm 0.050$ (2.5 th and 97 th percentiles: $0.314,0.511)$, and mean abundance was $701 \pm 79(548,855)$ green turtles in 2018 (Tables 3-5, Fig. 2). With conventional distance sampling in 2018, mean detectability of green turtles within $90 \mathrm{~m}$ of transect centrelines $P_{d}$ was $0.556 \pm 0.035(0.488$, 0.626), and mean abundance was $774 \pm 156$ (462, 1081) green turtles. Green turtle mean availability $P_{a}$ was $0.739 \pm 0.101(0.539,0.939)$.

\subsubsection{Hawksbill turtles}

We detected a mean \pm SD of $34 \pm 9$ hawksbill turtles $(\mathrm{CI}=21-57)$ per survey time period in February-May 
Table 2. Akaike's information criterion (AIC) values, differences and weights for the top 5 zero-inflated Poisson and Poissonbinomial mixture models with single site-specific or survey-specific covariates for green and hawksbill turtles based on transect-count surveys on the west coast of Bonaire and the entire coast of Klein Bonaire in February-May and net-capture surveys inside Lac Bay, southeast Bonaire, in June-December 2003-2018. For further information on N-mixture models see Section 2.2. q: number of parameters

\begin{tabular}{|c|c|c|c|c|c|c|}
\hline Survey & Species & Model & q & AIC & $\Delta \mathrm{AIC}$ & AIC weight \\
\hline \multirow[t]{10}{*}{ Transect count } & \multirow[t]{5}{*}{ Green $^{\mathrm{a}}$} & $\lambda($ region), $P(t)$ & 7 & 501.27 & 0.00 & 0.45 \\
\hline & & $\lambda($ region $), P(t$, counting time $)$ & 8 & 501.58 & 0.31 & 0.39 \\
\hline & & $\lambda$ (region), $P(t$, observer $)$ & 8 & 503.27 & 2.00 & 0.17 \\
\hline & & $\lambda$ (region), $P(t$, year $)$ & 8 & 524.07 & 22.80 & 0.00 \\
\hline & & $\lambda$ (region), $P(t$, month) & 8 & 526.28 & 25.01 & 0.00 \\
\hline & \multirow[t]{5}{*}{ Hawksbill $^{\mathrm{b}}$} & $\lambda(),. P(t)$ & 5 & 240.24 & 0.00 & 0.10 \\
\hline & & $\lambda$ (region), $P(t)$ & 6 & 240.33 & 0.09 & 0.09 \\
\hline & & $\lambda(),. P()$. & 2 & 241.02 & 0.78 & 0.06 \\
\hline & & $\lambda($ region), $P()$. & 3 & 241.07 & 0.83 & 0.06 \\
\hline & & $\lambda($ region $), P(t$, counting time $)$ & 7 & 241.33 & 01.09 & 0.06 \\
\hline \multirow{5}{*}{ Net capture } & \multirow{5}{*}{ Green $^{c}$} & $\lambda($ year $), P(t)$ & 6 & 618.27 & 0.00 & 0.18 \\
\hline & & $\lambda$ (year), $P(t$, netting time) & 7 & 619.11 & 0.84 & 0.12 \\
\hline & & $\lambda$ (year), $P(t$, year $)$ & 7 & 619.44 & 1.17 & 0.10 \\
\hline & & $\lambda$ (year), $P(t$, observer) & 7 & 619.60 & 1.33 & 0.09 \\
\hline & & $\lambda$ (year), $P(t$, month) & 7 & 619.76 & 1.49 & 0.08 \\
\hline
\end{tabular}

Table 3. Akaike's information criterion (AIC) values, differences and weights for the top 5 zero-inflated Poisson and Poissonbinomial mixture models with single site-specific or survey-specific covariates for green and hawksbill turtles based on transect-count surveys on the west coast of Bonaire and the entire coast of Klein Bonaire in February-May and net-capture surveys inside Lac Bay, southeast Bonaire, in June-December 2018; q: number of parameters

\begin{tabular}{|c|c|c|c|c|c|c|}
\hline Survey & Species & Model & $\mathrm{q}$ & AIC & $\Delta \mathrm{AIC}$ & AIC weight \\
\hline \multirow[t]{10}{*}{ Transect count } & \multirow[t]{5}{*}{ Green $^{\mathrm{a}}$} & $\lambda(),. P(t$, rubble $)$ & 7 & 675.74 & 0.00 & 0.51 \\
\hline & & $\lambda$ (region), $P(t$, rubble) & 8 & 677.08 & 1.64 & 0.11 \\
\hline & & $\lambda($ rubble),$P(t$, rubble) & 8 & 677.17 & 1.73 & 0.08 \\
\hline & & $\lambda($ rubble),$P(t)$ & 7 & 679.55 & 4.11 & 0.03 \\
\hline & & $\lambda(),. P(t$, counting time $)$ & 7 & 680.84 & 5.40 & 0.02 \\
\hline & \multirow[t]{5}{*}{ Hawksbill $^{\mathrm{b}}$} & $\lambda(),. P()$. & 3 & 346.29 & 0.00 & 0.19 \\
\hline & & $\lambda($ rubble),$P(.$, rubble) & 4 & 347.27 & 0.98 & 0.12 \\
\hline & & $\lambda(),. P(.$, observer $)$ & 3 & 347.41 & 1.12 & 0.11 \\
\hline & & $\lambda(),. P(.$, transect area $)$ & 3 & 347.77 & 1.48 & 0.09 \\
\hline & & $\lambda($ transect area), $P()$. & 3 & 348.11 & 1.82 & 0.08 \\
\hline \multirow[t]{5}{*}{ Net capture } & \multirow[t]{5}{*}{ Green $^{c}$} & $\lambda(),. P(t$, netting time $)$ & 6 & 255.41 & 0.00 & 0.99 \\
\hline & & $\lambda(),. P(t$, visibility $)$ & 6 & 277.33 & 21.92 & 0.00 \\
\hline & & $\lambda(),. P(t)$ & 5 & 278.13 & 22.72 & 0.00 \\
\hline & & $\lambda(),. P(t$, month $)$ & 6 & 278.15 & 22.74 & 0.00 \\
\hline & & $\lambda(),. P(t$, observer $)$ & 6 & 278.99 & 23.58 & 0.00 \\
\hline \multicolumn{7}{|c|}{ 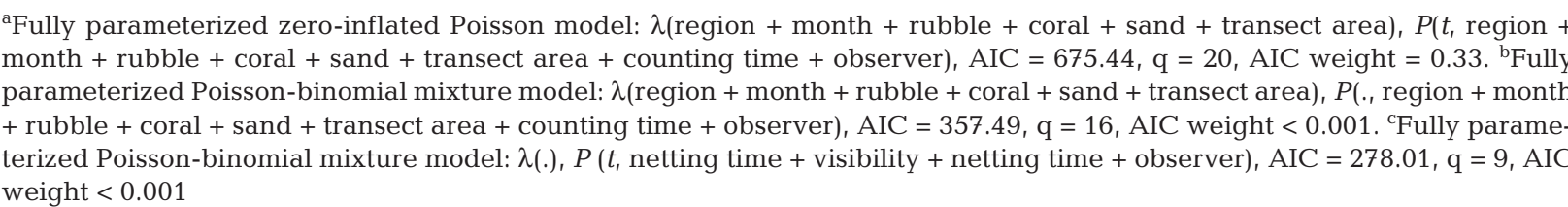 } \\
\hline
\end{tabular}

2003-2018. The fully-parameterized Poisson-binomial mixture model fit the data in 2003-2018 and $2018\left(\chi^{2}\right.$ $=16.39$ and $18.06, \mathrm{df}=19, \mathrm{p}=0.52$ and 0.63 , respec- tively; Tables 2 \& 3). Based on AIC values and weights in 2003-2018 (Table 2), the models with constant abundance $\lambda($.$) and survey-specific P(t)$ or con- 
Table 4. Annual abundance estimates with standard errors and 2.5th and 97.5th percentiles for green and hawksbill turtle transect-count surveys at northwest and southwest

Bonaire and Klein Bonaire in February-May 2018

\begin{tabular}{|llcccc|}
\hline \multirow{2}{*}{ Species } & Region & N & SE & 2.5th & 97.5th \\
\hline Green & Northwest Bonaire & 394 & 17 & 362 & 429 \\
& Southwest Bonaire & 207 & 15 & 180 & 239 \\
\multirow{5}{*}{ Hawksbill } & Klein Bonaire & 100 & 12 & 79 & 126 \\
& Northwest Bonaire & 42 & 3 & 37 & 48 \\
& Southwest Bonaire & 37 & 4 & 30 & 46 \\
& Klein Bonaire & 23 & 5 & 15 & 35 \\
\hline
\end{tabular}

Table 5. Green and hawksbill turtle transect-count annual abundance estimates with standard errors and 2.5th and 97.5th percentiles for the west coast of Bonaire and the entire coast of Klein Bonaire in February-May and green turtle net-capture annual abundance estimates with standard errors and 2.5 th and 97.5th percentiles for the interior of Lac Bay, southeast Bonaire, in June-December 2003-2018

\begin{tabular}{|c|c|c|c|c|c|c|}
\hline Survey & Species & Year & $\mathrm{N}$ & $\mathrm{SE}$ & 2.5 th & 97.5 th \\
\hline Transect count & Hawksbill & $\begin{array}{l}2003 \\
2004 \\
2005 \\
2006 \\
2007 \\
2008 \\
2009 \\
2010 \\
2011 \\
2012 \\
2013 \\
2014 \\
2015 \\
2016 \\
2017 \\
2018 \\
2003 \\
2004 \\
2005 \\
2006 \\
2007 \\
2008 \\
2009 \\
2010 \\
2011 \\
2012 \\
2013 \\
2014 \\
2015 \\
2016 \\
2017 \\
2018 \\
2003 \\
2004 \\
2005 \\
2006 \\
2007 \\
2008 \\
2009 \\
2010 \\
2011 \\
2012 \\
2013 \\
2014 \\
2015 \\
2016 \\
2017 \\
2018\end{array}$ & $\begin{array}{c}440 \\
538 \\
430 \\
481 \\
512 \\
506 \\
481 \\
710 \\
517 \\
596 \\
849 \\
272 \\
744 \\
461 \\
531 \\
701 \\
74 \\
68 \\
69 \\
102 \\
119 \\
93 \\
82 \\
62 \\
45 \\
50 \\
56 \\
36 \\
51 \\
51 \\
47 \\
70 \\
\mid\end{array}$ & $\begin{array}{c}66 \\
139 \\
72 \\
114 \\
109 \\
122 \\
152 \\
157 \\
139 \\
173 \\
437 \\
94 \\
196 \\
64 \\
142 \\
126 \\
16 \\
12 \\
16 \\
14 \\
15 \\
13 \\
12 \\
13 \\
9\end{array}$ & 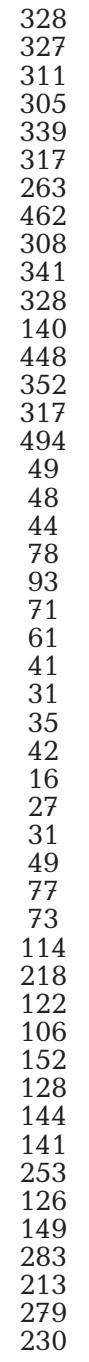 & $\begin{array}{c}590 \\
886 \\
595 \\
760 \\
775 \\
807 \\
880 \\
1090 \\
869 \\
1041 \\
2196 \\
525 \\
1236 \\
604 \\
889 \\
994 \\
112 \\
97 \\
107 \\
134 \\
154 \\
122 \\
110 \\
93 \\
65 \\
72 \\
74 \\
83 \\
96 \\
71 \\
100 \\
136 \\
166 \\
450 \\
530 \\
416 \\
391 \\
503 \\
744 \\
473 \\
538 \\
1204 \\
869 \\
1384 \\
895 \\
740 \\
1128 \\
1262\end{array}$ \\
\hline
\end{tabular}

stant detection probability $P($.$) were supported by the$ data; region was the most important abundance covariate $\left(\beta_{1}=0.282, \mathrm{SE}=0.122, \mathrm{CI}=0.125-0.635\right)$; and survey-specific detection probability was mainly influenced by counting time $\left(\beta_{1}=0.840, \mathrm{SE}=0.0 .297\right.$, $\mathrm{CI}=0.0 .429-1.646)$. The Poisson-binomial mixture models with transect average area covered by rubble and transect surveyed area as abundance covariates $\left(\beta_{1}=0.358, \mathrm{SE}=0.186, \mathrm{CI}=0.137-0.933\right.$ and $\beta_{1}=$ $0.215, \mathrm{SE}=0.119, \mathrm{CI}=0.078-0.592$, respectively) and constant detection probability were supported by the data in 2018 (Table 3). Transect average area covered by rubble $\left(\beta_{1}=0.322\right.$, $\mathrm{SE}=0.161$, $\mathrm{CI}=0.128-0.813)$, the number of observers $\left(\beta_{1}=1.251, \mathrm{SE}=0.295, \mathrm{CI}=\right.$ $0.793-1.974)$, and transect surveyed area $\left(\beta_{1}=0.215, \mathrm{SE}=0.119, \mathrm{CI}=\right.$ 0.078-0.592) also influenced detection probability; and region influenced abundance $\left(\beta_{1}=0.361, \mathrm{SE}=0.226, \mathrm{CI}=\right.$ 0.117-1.114; Table 3). Based on AIC values and weights, the Poisson-binomial mixture model with region and transect average area covered by rubble as abundance covariates and constant detection probability received support from the data (i.e. $\lambda$ [region + rubble], $P[],. \Delta$ AIC $=1.31, \mathrm{q}=4$, AIC weight $=0.08$ ). Transect average area covered by rubble and hawksbill turtle abundance were higher in northwest than southwest Bonaire and Klein Bonaire $(z=2.06-9.83$, all $\mathrm{p}<0.04$; Tables $1 \& 4$ ).

Mean \pm SE annual detection probability was $0.424 \pm 0.135$ (2.5th and 97.5 th percentiles $=0.230,0.780$ ) Mean annual abundance was $70 \pm 13$ $(49,101)$ hawksbill turtles (Table 5). Maximum likelihood and Bayesian GLMs generated similar results and showed no trends in annual abundance in 2003-2018 ( $\beta_{1}=-0.027$, $\mathrm{SE}=0.020, \mathrm{CI}=-0.065-0.012, z=$ $-1.34, \mathrm{p}=0.18$ and $\beta_{1}=-0.026, \mathrm{SD}=$ 0.017 , CI $=-0.058-0.008$, respectively; Table 5, Fig. 3). Realizations of Markov chains and node summary statistics showed convergence of the MCMC algorithm for Bayesian GLMs $(R=1.00-1.01)$.

Based on $N$-mixture model averaging, mean \pm SE detection probability 


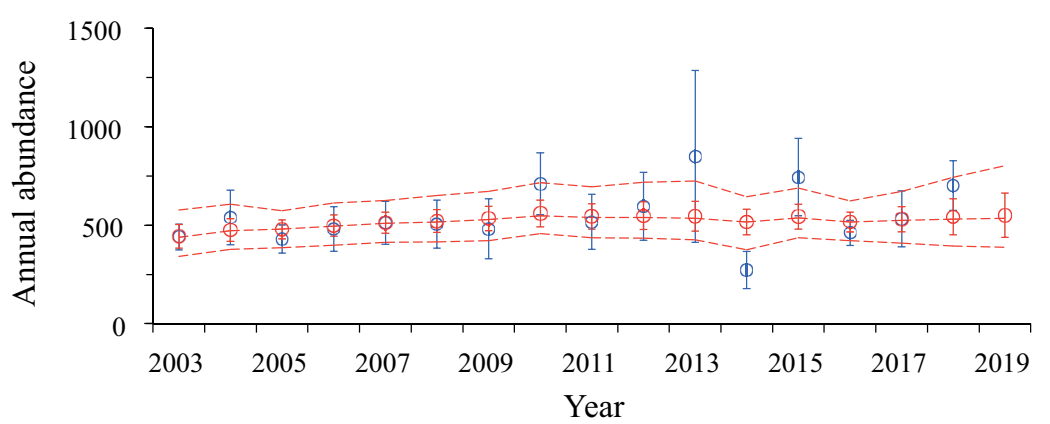

Fig. 2. Green turtle $N$-mixture model abundance estimates (blue circles, with bootstrapped standard errors) from transect-count surveys in February-May 2003-2018, and Bayesian state-space logistic model means (red circles, with Markov chain Monte Carlo standard deviations) and medians with 2.5 th and 97.5 th percentiles (red dashed lines) under low human-induced mortality rates $(m<0.100)$ along the west coast of Bonaire and the entire coast of Klein Bonaire in 2003-2019

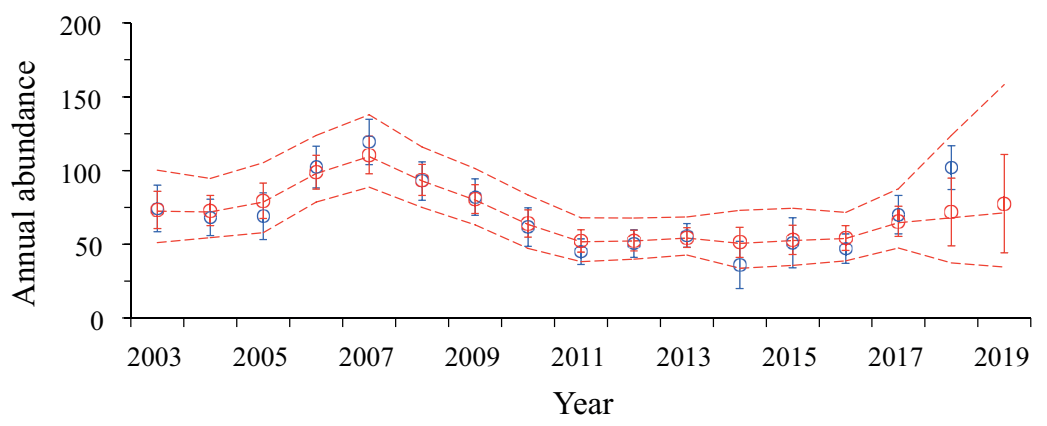

Fig. 3. As in Fig. 2, but for hawksbill turtles

$P_{d a}$ was $0.393 \pm 0.093(0.249,0.620)$ and mean abundance was $102 \pm 15(73,132)$ hawksbill turtles in 2018 (Tables 3-5, Fig. 3). With conventional distance sampling in 2018, mean detectability of hawksbill turtles within $90 \mathrm{~m}$ of transect centrelines $P_{d}$ was 0.792 $\pm 0.234(0.449,1.000)$ and mean abundance was 119 $\pm 49(22,214)$ hawksbill turtles. Hawksbill turtle mean availability for detection $P_{a}$ was $0.484 \pm 0.185(0.132$, 0.844).

\subsection{Net-capture surveys in Lac Bay}

We captured an average of $2 \pm 1$ hawksbill turtles (mean $\pm \mathrm{SD}_{i} 95 \% \mathrm{CI}=0-3$ ) and $63 \pm 25(32-94)$ green turtles per survey time period in June-December 2003-2018. Hawksbill turtles were excluded from the analysis due to the low number of captures. The fully parameterized Poisson-binomial mixture model fit the green turtle net-capture survey data in 2003-2018 and $2018\left(\chi^{2}=19.08\right.$ and 19.81, $\mathrm{df}=18, \mathrm{p}=$ 0.32 and 0.34, respectively; Tables $2 \& 3$ ). Based on AIC values and weights in 2003-2018 (Table 2), year was the most important abundance covariate $\left(\beta_{1}=0.078, \mathrm{SE}=0.018, \mathrm{CI}=\right.$ $0.050-0.122)$; and survey-specific capture probability was influenced by netting time $\left(\beta_{1}=0.016, \mathrm{SE}=0.001, \mathrm{CI}=\right.$ $0.014-0.018)$, year $\left(\beta_{1}=0.019, \mathrm{SE}=\right.$ $0.012, \mathrm{CI}=0.006-0.059$ ), the number of observers $\left(\beta_{1}=0.036, \mathrm{SE}=0.022, \mathrm{CI}=\right.$ $0.012-0.109)$ and month $\left(\beta_{1}=0.065\right.$, $\mathrm{SE}=0.037, \mathrm{CI}=0.023-0.184)$. The Poisson-binomial mixture model with constant abundance and survey-specific capture probability with netting time as a capture probability covariate $\left(\beta_{1}=0.395, \mathrm{SE}=0.144, \mathrm{CI}=0.198-\right.$ 0.789 ) received support from the data in 2018 (Table 3).

Based on $N$-mixture model averaging, mean $\pm \mathrm{SE}$ annual capture probability was $0.151 \pm 0.078$ (2.5th and 97.5th percentiles $=0.058,0.393$ ) and mean annual abundance was $348 \pm 135$ (171, 731) green turtles in 2003-2018 (Tables 2 \& 5, Fig. 4). With the multiple Lincoln-Peterson method in 2003-2018, mean annual capture probability was $0.126 \pm 0.053(0.057,0.277)$ and mean annual abundance was $323 \pm 89$ (190, 549) green turtles. Maximum likelihood and Bayesian GLMs generated similar results and showed positive trends in annual abundance in 2003-2018 $\left(\beta_{1}=0.077, \mathrm{SE}=0.015, \mathrm{CI}=\right.$ $0.049-0.106, z=5.29, \mathrm{p}<0.001$ and $\beta_{1}=0.077, \mathrm{SD}=$ 0.015, CI = 0.049-0.106, respectively; Table 5, Fig. 4). Realizations of Markov chains and node summary statistics showed convergence of the MCMC algorithm for Bayesian GLMs $(R=1.00-1.04)$.

\subsection{Bayesian state-space logistic model}

For green turtles in western Bonaire and Klein Bonaire (Figs. 1A \& 2), mean \pm SD population carrying capacity was $870 \pm 595$ individuals (median = $634,2.5$ th and 97.5 th percentiles $=515,2987$ ), mean maximum population growth rate was $0.461 \pm 0.275$ (median $=0.430,2.5$ th and 97.5 th percentiles $=$ $0.105,0.966)$, mean equilibrium population abundance was $435 \pm 297$ individuals (median $=317,2.5$ th and 97.5 th percentiles $=257,1449$ ), mean maximum sustainable human-induced mortality rate was $0.231 \pm$ 0.137 (median $=0.215,2.5$ th and 97.5 th percentiles $=$ $0.053,0.483)$, mean maximum sustainable total num- 


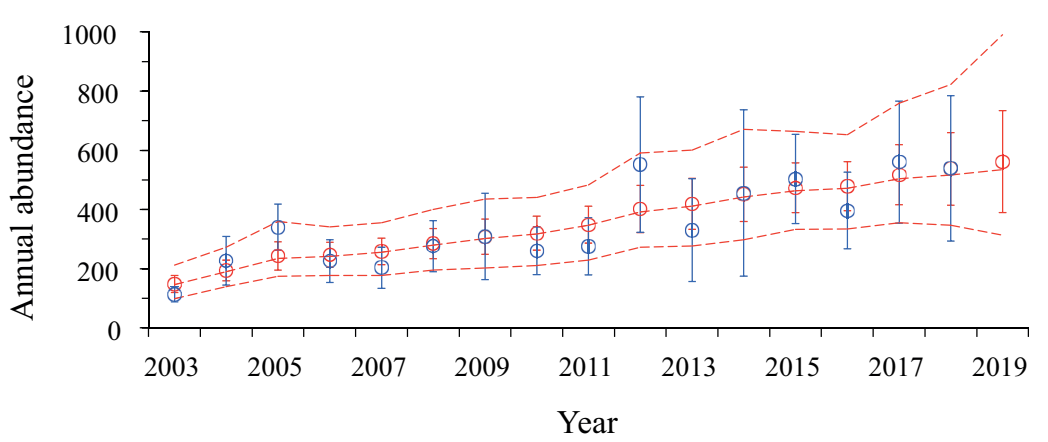

Fig. 4. Green turtle $N$-mixture model and multiple Lincoln-Petersen method abundance estimates (blue circles, with bootstrapped standard errors) from net-capture surveys in June-December 2003-2018, and Bayesian state-space logistic model means (red circles, with Markov chain Monte Carlo standard deviations) and medians with 2.5 th and 97.5 th percentiles (red dashed lines) under low human-induced mortality rates $(m<0.100)$ inside Lac Bay, southeast Bonaire, in 2003-2019

ber of deaths from human-induced mortality was 78 \pm 34 individuals (median $=74,2.5$ th and 97.5 th percentiles $=26,143)$, and mean process variance was $0.013 \pm 0.022$ (median $=0.005,2.5$ th and 97.5 th percentiles $=0.000,0.071)$. Mean predicted abundance was $550 \pm 112$ green turtles in 2019 (median $=535$, 2.5 th and 97.5 th percentiles $=389,801$; Fig. 2 ) and $576 \pm 198$ green turtles in 2020-2030 (median $=542$, 2.5 th and 97.5th percentiles $=362,1030$ ). Predicted abundance was highly uncertain mainly because of process variance (mean $\mathrm{CV}_{\text {process }}=1.69$ vs. mean $\mathrm{CV}_{\text {survey }}=0.26$ ). Realizations of Markov chains and node summary statistics showed convergence of the MCMC algorithm for the Bayesian state-space logistic model $(R=1.00-1.05)$.

For hawksbill turtles in western Bonaire and Klein Bonaire (Figs. 1A \& 3), mean \pm SD population carrying capacity was $223 \pm 111$ individuals (median $=186$, 2.5 th and 97.5 th percentiles $=102,471$ ), mean maximum population growth rate was $0.197 \pm 0.094$ (median $=0.168,2.5$ th and 97.5 th percentiles $=0.103$, 0.457 ), mean equilibrium population abundance was $122 \pm 56$ individuals $($ median $=93,2.5$ th and 97.5 th percentiles $=51,236)$, mean maximum sustainable human-induced mortality rate was $0.099 \pm 0.047$ (median $=0.084,2.5$ th and 97.5 th percentiles $=0.051$, 0.229), mean maximum sustainable total number of deaths from human-induced mortality was $10 \pm 6$ individuals (median $=9,2.5$ th and 97.5 th percentiles $=$ $3,25)$, and mean process variance was $0.066 \pm 0.051$ $($ median $=0.053,2.5$ th and 97.5 th percentiles $=0.014$, 0.197). Mean predicted abundance was $78 \pm 33$ hawksbill turtles in 2019 (median $=71,2.5$ th and 97.5th percentiles $=35,158$; Fig. 3) and $101 \pm 65$ hawksbill turtles in 2020-2030 (median $=86,2.5$ th and 97.5 th percentiles $=28,267$ ). Predicted abundance was highly uncertain, mainly because of process variance (mean $\mathrm{CV}=0.77 \mathrm{vs}$. mean $\mathrm{CV}_{\text {survey }}=0.21$ ). Realizations of Markov chains and node summary statistics showed convergence of the MCMC algorithm for the Bayesian statespace logistic model $(R=1.00-1.02)$.

For green turtles inside Lac Bay (Figs. 1B \& 4), mean \pm SD population carrying capacity was $688 \pm 532$ individuals (median $=474,2.5$ th and 97.5 th percentiles $=311,2414$ ), mean maximum population growth rate was $0.372 \pm 0.184$ (median $=0.345,2.5$ th and 97.5 th percentiles $=0.104,0.750$ ), mean equilibrium population abundance was $344 \pm 266$ individuals (median $=237,2.5$ th and 97.5 th percentiles $=156,1207$ ), mean maximum sustainable human-induced mortality rate was $0.186 \pm 0.092$ (median $=0.173,2.5$ th and 97.5 th percentiles $=0.052,0.375$ ), mean maximum sustainable total number of deaths from human-induced mortality was $64 \pm 35$ individuals (median = $58,2.5$ th and 97.5 th percentiles $=21,154$ ), and mean process variance was $0.063 \pm 0.057$ (median $=0.047$, 2.5 th and 97.5 th percentiles $=0.005,0.217$ ). Mean predicted abundance was $590 \pm 396$ green turtles in 2019 (median $=506,2.5$ th and 97.5 th percentiles $=$ $160,1488)$ and $700 \pm 626$ green turtles in 2020-2030 (median $=542,2.5$ th and 97.5 th percentiles $=79$, 2306). Predicted abundance was highly uncertain, mainly because of process variance (mean $\mathrm{CV}_{\text {process }}=$ 0.90 vs. mean $C_{\text {survey }}=0.37$ ). Realizations of Markov chains and node summary statistics showed convergence of the MCMC algorithm for the Bayesian statespace logistic model $(R=1.00-1.03)$.

\section{DISCUSSION}

The survey-based and model-based methodology implemented can be adapted to estimate sea turtle annual abundance, monitor and model their population dynamics and assess the negative impact of human-induced mortality in other Caribbean islands. We obtained similar abundance estimates with $N$ mixture models, conventional distance sampling and the multiple Lincoln-Petersen method, and similar trends in annual abundance with maximum likelihood and Bayesian GLMs. In addition, although we made a number of simplifying assumptions (e.g. linear density dependence and equal mortality for all sea turtles), the Bayesian state-space logistic model 
generated useful baselines for maximum population growth rate, population carrying capacity, maximum sustainable human-induced mortality and predicted abundance, despite insufficient data about local and regional movements, sex-specific and age-specific demographic rates and the number of green and hawksbill turtles killed annually by fishing, poaching, boating and other human activities. Below, we discuss the results and provide recommendations for monitoring and modelling green and hawksbill turtle populations at foraging grounds in the coastal waters of Bonaire and Klein Bonaire.

\subsection{Transect-count surveys in western Bonaire and Klein Bonaire}

Region and transect average area covered by rubble had positive effects on green and hawksbill turtle abundance (Tables 1-4). Green and hawksbill turtle abundance and transect average area covered by rubble were higher in northwest Bonaire than in southwest Bonaire and Klein Bonaire (Table 4). Although other explanations are plausible and cannot be ruled out with the available data (e.g. predator abundance and predation risk; see Heithaus et al. 2005), we suggest that regional differences in abundance were related to the quality and quantity of foraging resources available at the most common bottom substrate in the surveyed areas (León \& Bjorndal 2002, Patrício et al. 2014, Bjorndal et al. 2017, Christianen et al. 2019). In addition, transect surveyed area had a positive effect on hawksbill turtle abundance, but not on green turtle abundance (Table 3). However, food preference, foraging behaviour and habitat use vary with species and life stage, and, not surprisingly, large transect surveyed areas may have more foraging resources than small transect surveyed areas.

Counting time, the number of observers and transect average area covered by rubble had positive effects on green and hawksbill turtle detection probability (Tables $2 \& 3$ ). In addition, transect surveyed area had a positive effect on hawksbill turtle detection probability, but not on green turtle detection probability (Table 3 ). Although the positive effects of counting time and the number of observers were unsurprising, the positive effects of transect average area covered by rubble and transect surveyed area were unexpected, and may be explained by the sharp contrast between the bottom substrate and sea turtle carapace colouration, as well as other speciesspecific differences in the 2 components of detection probability. Detectability was higher and availability was lower for hawksbill turtles than for green turtles. Species-specific differences in detection probability may be related to multiple factors, including behavioural responses and strategies to avoid detection by the observers, which may be perceived as predators (e.g. diving and relying on camouflage while hiding motionless inside crevices vs. changing direction and swimming away; see Bevan et al. 2018).

After transect counts were corrected for detection probability, mean annual abundance was about 500 green turtles and 70 hawksbill turtles, and GLMs showed no trends in annual abundance (Table 5, Figs. 2 \& 3). Although green and hawksbill turtle annual abundance remained stable over $16 \mathrm{yr}$, longer time periods may be required to detect negative and positive trends (Bjorndal et al. 2005, Chaloupka et al. 2008, García-Cruz et al. 2015, Mazaris et al. 2017). Therefore, considering the results, we recommend: (1) expanding the survey sampling scheme to cover the entire coasts of Bonaire and Klein Bonaire; (2) repeating counts 3 times per transect in FebruaryMay; and (3) using $N$-mixture and distance sampling models to estimate annual abundance corrected for detection probability (Royle 2004, Kéry et al. 2009, Kéry \& Schaub 2012, Buckland et al. 2015).

\subsection{Net-capture surveys in Lac Bay}

Year had positive effects on green turtle abundance and capture probability (Table 2). Netting time, the number of observers and month also had positive effects on capture probability (Tables $2 \& 3$ ). After net captures were corrected for capture probability, mean annual abundance was about 300 green turtles, but GLMs showed positive trends in annual abundance, with about 100 green turtles in 2003 and about 500 green turtles in 2018 (Table 5, Fig. 4). The positive trend in annual abundance inside Lac Bay may be explained by the attraction of juvenile green turtles from rookeries with stable or increasing abundances across the Caribbean (Chaloupka et al. 2008, Kubis et al. 2009, Mazaris et al. 2017, Christianen et al. 2019, J. Van der Zee pers. comm.). However, the increase in green turtle annual abundance coincided with the introduction and expansion of the invasive seagrass Halophila stipulacea, which ultimately may reduce the diversity and quality of foraging resources and interact with other natural and anthropogenic disturbances to cause a decline, despite local and regional conservation efforts to maintain or enhance population levels (Saba et al. 
2012, Van Tussenbroek et al. 2014, Bjorndal et al. 2017, Schut et al. 2018, Christianen et al. 2019). Therefore, collaborative question-driven research and targeted monitoring are needed to assess the results of conservation actions and better understand the biological and environmental factors driving trends in annual abundance (Nichols \& Williams 2006, Lindenmayer \& Likens 2010, Bjorndal et al. 2017, Schut et al. 2018, Christianen et al. 2019). Considering the results, we recommend: (1) conducting 5 visits per point in a short survey time period, e.g. June-August, when weather conditions are relatively stable; (2) measuring site-specific covariates, such as the abundance of native and invasive seagrasses per netting point; and (3) using $N$-mixture and spatial capture-mark-recapture models to estimate abundance corrected for capture probability (Royle 2004, Kéry et al. 2009, Kéry \& Schaub 2012, Royle et al. 2013).

\subsection{Population parameters and abundance predictions}

The Bayesian state-space logistic model generated useful baselines for population parameter posterior distributions and abundance predictions in 20192030. For example, model-based simulations showed that green turtles have higher population growth rate and population carrying capacity, and therefore have higher equilibrium population abundance $\left(N_{\text {eq }}=K / 2\right)$ and can sustain higher human-induced mortality $\left(M_{\mathrm{ms}}=r_{\max } K / 4\right.$ and $\left.m_{\mathrm{ms}}=r_{\max } / 2\right)$ than hawksbill turtles in the surveyed areas. However, under low human-induced mortality rates $(m<0.100)$, green and hawksbill turtles can fluctuate stably between the lower and upper limits of population carrying capacity (Figs. 2-4).

Short-term abundance predictions were highly imprecise mainly because process variance was included in the model. In addition, because the model did not account for other potential threats, such as the degradation of foraging resources by invasive seagrasses, coastal development and climate change, abundance predictions should be taken only as suggestive of green and hawksbill turtle numbers in the surveyed areas during the modelled time horizon. Therefore, considering the results, we recommend: (1) designing in-person surveys to estimate the total number of deaths from human-induced mortality per year; (2) conducting community outreach and education efforts targeting fishermen, boaters and other resource users; and (3) developing the Bayesian state-space modelling framework to combine transect count, net capture, satellite telemetry and nest-monitoring data (Levy \& Lemeshow 1999, Johnson et al. 2010, Kéry \& Schaub 2012, Zipkin \& Saunders 2018). In the meantime, we can continue updating the Bayesian state-space logistic model annually with transect-count and netcapture survey data to gain precision from long-term monitoring and learn from the comparison of modelbased abundance predictions and survey-based abundance estimates, despite incomplete understanding of green and hawksbill turtle population dynamics, and partial or no control over natural and anthropogenic disturbances at foraging grounds in the coastal waters of Bonaire and Klein Bonaire.

Acknowledgements. We thank STCB volunteers and interns for their dedication and assistance with fieldwork. Special thanks to STCB Field Specialist Gielmon 'Funchi' Egbreghts, former Project Director and Scientific Advisor Robert Van Dam, former Field Coordinator Sue Willis, 2018 intern Mavelly Velandia and WIDECAST Director Karen Eckert. Our gratitude to World Wildlife Fund-Netherlands, Stichting DierenLot, the Ministry of Economic Affairs and the donors who have supported STCB activities since 1991. John Mickelson, GIS Specialist, prepared the transect-count and net-capture survey maps. Two anonymous reviewers helped to improve the manuscript.

\section{LITERATURE CITED}

Acock AC (2016) A gentle introduction to STATA, $5^{\text {th }}$ edn. STATA Press Publication, College Station, TX

Becking LE, Christianen MJA, Nava MI, Miller N, Willis S, Van Dam RP (2016) Post-breeding migration routes of marine turtles from Bonaire and Klein Bonaire, Caribbean Netherlands. Endang Species Res 30:117-124

Bevan E, Whiting S, Tucker T, Guinea M, Raith A, Douglas $\mathrm{R}$ (2018) Measuring behavioural responses of sea turtles, saltwater crocodiles, and crested terns to drone disturbance to define ethical operating thresholds. PLOS ONE 13:e0194460

Bjorndal K, Bolten AB, Chaloupka MY (2005) Evaluating trends in abundance of immature green turtles, Chelonia mydas, in the greater Caribbean. Ecol Appl 15:304-314

* Bjorndal K, Bolten AB, Chaloupka M, Saba VS and others (2017) Ecological regime shift drives declining growth rates of sea turtles throughout the West Atlantic. Glob Change Biol 23:4556-4568

Buckland ST, Anderson DR, Burnham KP, Laake JL, Borchers DL, Thomas L (2001) Introduction to distance sampling. Oxford University Press, New York, NY

Buckland ST, Rexstad EA, Marques TA, Oedekoven CS (2015) Distance sampling: methods and applications. Springer, New York, NY

Burton FJ, Rivera-Milán FF (2014) Monitoring a population of translocated Grand Cayman blue iguanas: assessing the accuracy and precision of distance sampling and repeated counts. Amin Conserv 17:40-47

Casale P, Heppell SS (2016) How much sea turtle bycatch is too much? A stationary age distribution model for simu- 
lating population abundance and potential biological removal in the Mediterranean. Endang Species Res 29: 239-254

Chaloupka M, Balazs GH (2007) Using Bayesian state-space modelling to assess the recovery and harvest potential of the Hawaiian green sea turtle stock. Ecol Model 205: 93-109

* Chaloupka M, Bjorndal KA, Balazs GH, Bolten AB and others (2008) Encouraging outlook for recovery of a once severely exploited marine megaherbivore. Glob Ecol Biogeogr 17:297-304

Christianen MJA, Smulders FOH, Engel MS, Nava MI and others (2019) Megaherbivores may impact expansion of invasive seagrass in the Caribbean. J Ecol 107:45-57

Faraway JJ (2006) Extending the linear model with R. Chapman \& Hall/CRC, Boca Raton, FL

Fiske I, Chandler R, Miller D, Royle A and others (2019) Package UNMARKED 0.12-3. https://www.crantastic.org/ packages/unmarked/versions/80304 (accessed 9 September 2019)

García-Cruz MA, Lampo M, Peñazola CL, Kendall WL, Solé G, Rodríguez-Clark KM (2015) Population trends and survival of nesting green sea turtles Chelonia mydas on Aves Island, Venezuela. Endang Species Res 29:103-116

Gelman A, Hill J (2007) Data analysis using regression and multilevel/hierarchical models. Cambridge University Press, New York, NY

Grimm A, Gruber B, Henle K (2014) Reliability of different mark-recapture methods for population size estimation tested against reference population sizes constructed from field data. PLOS ONE 9:e98840

Haghish EF (2016) Rcall: seamless R in STATA. www. haghish.com/packages/Rcall.php (accessed 9 September 2019)

Heithaus MR, Frid A, Wirsing AJ, Bejder L, Dill ML (2005) Biology of sea turtles under risk from tiger sharks at a foraging ground. Mar Ecol Prog Ser 288:285-294

Hines JE (2019) PRESENCE: software to estimate patch occupancy and related parameters. US Geological Survey, Patuxent Wildlife Research Centre, Laurel, MD. www. mbr-pwrc.usgs.gov/software/presence.html (accessed 9 September 2019)

Hostetler JA, Chandler RB (2015) Improved state-space models for inference about spatial and temporal variation in abundance from count data. Ecology 96:1713-1723

Johnson HE, Mills LS, Wehausen JD, Stephenson TR (2010) Combining ground count, telemetry, and mark-resight data to infer population dynamics in an endangered species. J Appl Ecol 47:1083-1093

Kéry M, Schaub M (2012) Bayesian population analysis using WinBUGS: a hierarchical perspective. Elsevier, Waltham, MA

Kéry M, Dorazio RM, Soldaat L, Strien AV, Zuiderwijk A, Royle JA (2009) Trend estimation in populations with imperfect detection. J Appl Ecol 46:1163-1172

Kubis S, Chaloupka M, Ehrhart L, Bresette M (2009) Growth rates of juvenile green turtles Chelonia mydas from three ecologically distinct foraging habitats along the east coast of Florida, USA. Mar Ecol Prog Ser 389:257-269

León YM, Bjorndal KA (2002) Selective feeding in the hawksbill turtle, an important predator in coral reef ecosystems. Mar Ecol Prog Ser 245:249-258
Levy PS, Lemeshow S (1999) Sampling of populations. Wiley, New York, NY

Lindenmayer DB, Likens GE (2010) The science and application of ecological monitoring. Biol Conserv 143:1317-1328

Mazaris AD, Schofield G, Gkazinou C, Almpanidou V, Hays GC (2017) Global sea turtle conservation success. Sci Adv 3:e1600730

Newman KB, Buckland ST, Morgan BJT, King R and others (2014) Modelling population dynamics: model formulation, fitting and assessment using state-space methods. Springer, New York, NY

Nichols JD, Williams BK (2006) Monitoring for conservation. Trends Ecol Evol 21:668-673

* Patrício R, Diez CE, van Dam RP (2014) Spatial and temporal variability of immature green turtle abundance and somatic growth in Puerto Rico. Endang Species Res 23: $51-62$

* Plummer M (2003) JAGS: a program for analysis of Bayesian graphical models using Gibbs Sampling. www.r-project. org/conferences/DSC-2003/Proceedings/Plummer.PDF (accessed 9 Sep 2019)

R Development Core Team (2018) R: a language and environment for statistical computing. R Foundation for Statistical Computing, Vienna

Rivera-Milán FF, Simal F, Bertuol P, Boomer GS (2018) Population monitoring and modelling of yellow-shouldered parrot on Bonaire, Caribbean Netherlands. J Wildl Biol 1: wlb.00384

Royle JA (2004) N-mixture models for estimating population size from spatially replicated counts. Biometrics 60:108-115

Royle JA, Chandler RB, Sollmann R, Gardner B (2013) Spatial capture-recapture. Elsevier, Waltham, MA

Saba VS, Stock SA, Spotila JR, Paladino FV, Tomillo PS (2012) Projected response of an endangered marine turtle population to climate change. Nat Clim Chang 2:814-820

Schut K, Nava M, Rivera-Milán FF (2018) Sea Turtle Conservation Bonaire: research and monitoring of Bonaire's sea turtles. 2018 Tech Rep. STCB, Kralendijk. www.bonaireturtles.org (accessed 9 September 2019)

* Strindberg S, Coleman RA, Burns Pérez VR, Campbell CL, Majil I, Gibson J (2016) In-water assessments of sea turtles at Glover's Reef Atoll, Belize. Endang Species Res 31: 211-225

Su JS, Yajima M (2015) Using R to run JAGS. https://cran. r-project.org/web/packages/R2jags/R2jags.pdf (accessed 9 September 2019)

Thomas L, Marques TA (2012) Passive acoustic monitoring for estimating animal density. Acoust Today 8:35-44

Thomas L, Buckland ST, Rexstad EA, Laake JL and others (2010) Distance software: design and analysis of distance sampling surveys for estimating population size. J Appl Ecol 47:5-14

Thompson J (2014) Bayesian analysis with STATA. STATA Press Publication, College Station, TX

*Van Tussenbroek BI, Cortés J, Collin R, Fonseca AC and others (2014) Caribbean-wide, long-term study of seagrass beds reveals local variations, shifts in community structure and occasional collapse. PLOS ONE 9:e90600

Z Zeileis A (2004) Econometric computing with HC and HAC covariance matrix estimators. J Stat Softw 11:1-17

Zipkin EF, Saunders SP (2018) Synthesizing multiple data types for biological conservation using integrated population models. Biol Conserv 217:240-250

Submitted: February 20, 2019; Accepted: October 7, 2019

Proofs received from author(s): November 21, 2019 